\title{
The preservation of methanesulphonic acid in frozen ice-core samples
}

\author{
Nerilie J. ABRAM, ${ }^{1}$ Mark A.J. CURRAN, ${ }^{2}$ Robert MULVANEY, ${ }^{1}$ Tessa VANCE ${ }^{2}$ \\ ${ }^{1}$ British Antarctic Survey, Natural Environment Research Council, Madingley Road, Cambridge CB3 OET, UK \\ E-mail: NABR@bas.ac.uk \\ ${ }^{2}$ Australian Antarctic Division, and Antarctic Climate and Ecosystems CRC, Private Bag 80, Hobart, Tasmania 7001, Australia
}

\begin{abstract}
Ice-core records of methanesulphonic acid (MSA) provide a potentially powerful tool for producing proxy records of sea ice, a critical but poorly understood component of the Earth's climate system. However, MSA is able to diffuse through solid ice, and here we examine the effect of two different methods of frozen storage on the preservation of MSA in archived ice-core samples. Re-analysis of archived ice sticks confirms that MSA diffuses out of ice cores archived in this manner. Despite MSA losses of up to $39 \%$ after 7 years storage, the ice sticks studied here preserve much of the variability of the original MSA record, suggesting that useful proxy records can be obtained from archived ice sticks. Furthermore, re-analysis of ice-core samples that had been refrozen into discrete bottled samples for storage demonstrates that it is possible to archive ice samples in a way that prevents MSA loss. In this case, accurate records of MSA variability and concentration were preserved even over storage periods of 15 years. This has important implications for the storage of ice cores and subsequent determination of MSA, and demonstrates that ice storage history needs to be considered when interpreting MSA records.
\end{abstract}

\section{INTRODUCTION}

Over the past decade, records of methanesulphonic acid (MSA; $\mathrm{CH}_{3} \mathrm{SO}_{3} \mathrm{H}$ ) from ice cores have been explored as potential palaeoenvironmental proxies. MSA is ultimately derived from marine phytoplankton that live in high abundances at the Antarctic sea-ice margin (Curran and Jones, 2000). These algae produce dimethlysulphide (DMS), which is rapidly oxidized in the atmosphere to produce sulphate and methanesulphonic acid (Ravishankara and others, 1997). This is the only known source of MSA in Antarctic ice, leading to theories that MSA records from near-coastal ice cores could provide reconstructions of past biological activity and sea-ice conditions (Saigne and Legrand, 1987; Welch and others, 1993).

Initial results have shown that at some sites MSA variability is a good proxy for winter sea ice (Curran and others, 2003; Foster and others, 2006), while in other locations atmospheric transport strength provides the dominant control on the amount of MSA reaching the Antarctic continent (Pasteur and others, 1995; Fundel and others, 2006; Abram and others, 2008). Arrays of near-coastal ice-core sites further show that MSA records are representative of local to regional-scale conditions, and over the past century Antarctic ice cores suggest that there have been substantial regional differences in the variability and timing of sea-ice decline around Antarctica (Abram and others, unpublished data). All these factors mean that networks of ice-core MSA records are needed to develop a robust understanding of how Antarctic sea ice has changed in the past.

One way of developing more comprehensive networks of Antarctic MSA records is to re-analyze the chemistry of archived ice cores that were collected and analyzed before the measurement of MSA became routine. It is known, however, that over time MSA migrates through firn and ice (Mulvaney and others, 1992; Pasteur and Mulvaney, 1999, 2000; Curran and others, 2002; Smith and others, 2004). It has been hypothesized that MSA migration in solid ice is the result of diffusional movement of liquid-phase MSA-water mixtures along grain boundaries (Mulvaney and others, 1992; Pasteur and Mulvaney, 2000; Smith and others, 2004). Within the ice sheet, MSA diffuses vertically against chemical gradients, moving towards layers with higher concentrations of ionic species (e.g. winter layers) where it may form a stable insoluble salt with a cation (Mulvaney and others, 1992; Pasteur and Mulvaney, 2000; Curran and others, 2002). This vertical migration disturbs the seasonal character of MSA in ice, but for late-Holocene records diffusion appears to be limited to sub-annual scales and does not significantly alter the interannual MSA record. However, once an ice core has been drilled, it has been shown that MSA is able to diffuse out of the core while in frozen storage (Smith and others, 2004). This produces a gradual loss of MSA from the margins of stored ice cores.

In order to utilize MSA measurements from archived icecore samples, it is necessary to understand how different storage methods affect the migration and loss of MSA, and what influence this has on the MSA record retained in archived ice samples. In this study, we test the preservation of MSA by re-analyzing ice-core samples that have been stored frozen for a number of years following an initial chemical analysis that included MSA measurements. Two different storage methods are investigated: the first examines the preservation of MSA in sticks of ice cut from ice cores, and the second uses discrete samples where ice-core samples were melted and then refrozen in bottles.

\section{STICK SAMPLES: METHODS AND RESULTS}

The preservation of MSA records in frozen ice sticks was examined using a core from Law Dome. The DSS99 ice core was drilled by the Australian Antarctic Division at the Dome Summit South site in 1999. The ice core was shipped to Australia and stored at $-18^{\circ} \mathrm{C}$. The $140 \mathrm{~m}$ long core was cut vertically to provide parallel sticks of ice from the length of each core section for chemical analysis. Each chemistry stick was approximately $1 \mathrm{~m}$ long, with a square depth and width 

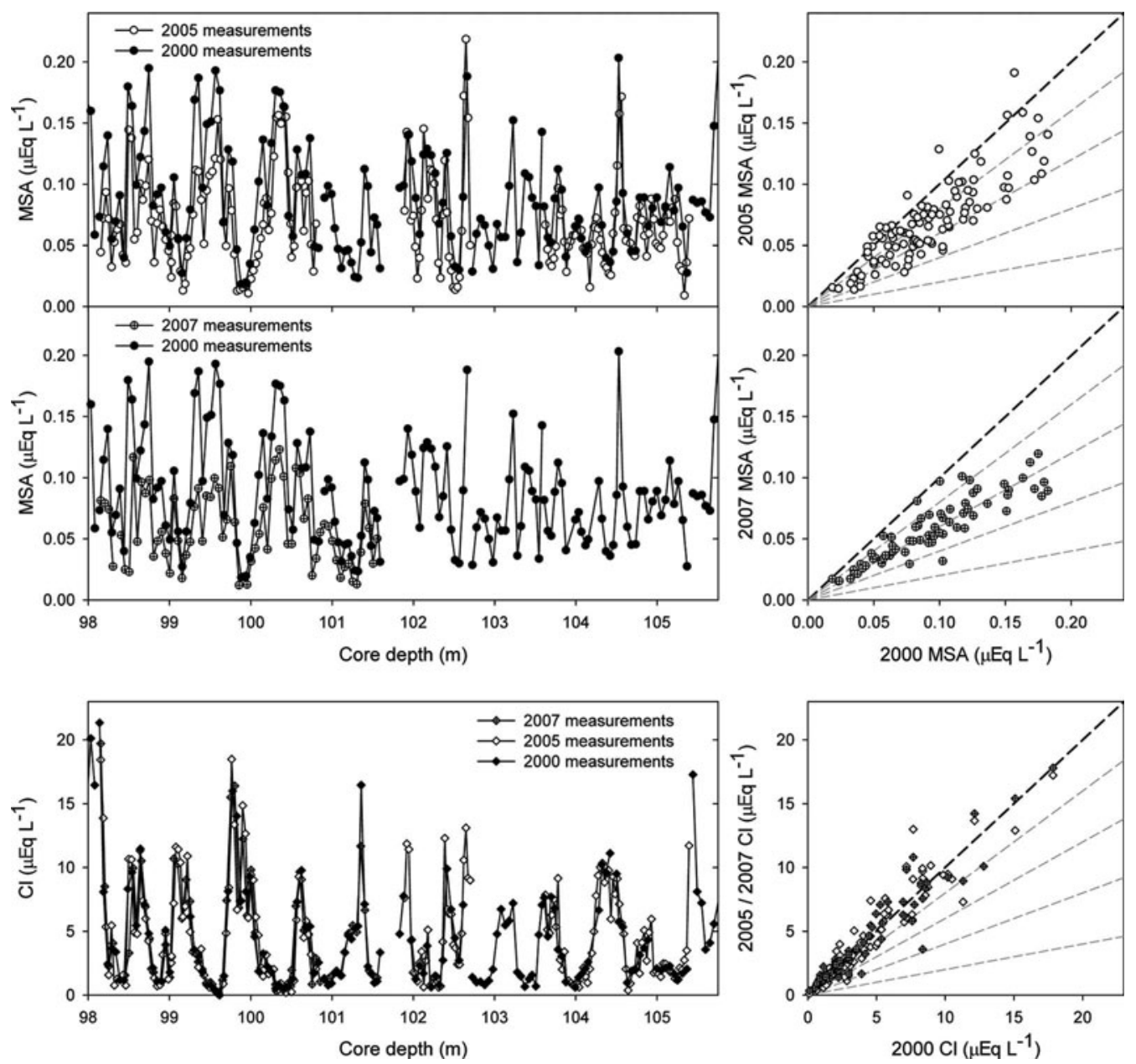

Fig. 1. Comparison of measurements of methanesulphonic acid (MSA) and chloride (Cl) in ice sticks from the Law Dome DSS99 ice core made during 2000, 2005 and 2007. In the right-side panels the black dashed line represents the $1: 1$ line between early and recent chemical measurements (i.e. $0 \%$ loss during storage). Grey dashed lines then show the expected relationship for scenarios of $20 \%, 40 \%, 60 \%$ and $80 \%$ loss during storage, respectively. Loss of $\mathrm{Cl}$ during frozen storage is negligible for the ice sticks, whereas MSA shows losses of $24 \pm 4 \%$ after 5 years of storage, and $39 \pm 3 \%$ after 7 years of storage.

of $3.5 \mathrm{~cm}$. A 'D-shaped' (half-core) section was also retained as an archive along the length of the DSS99 core.

During 2000, frozen stick samples from the DSS99 core were analyzed for MSA and other ions using a Dionex ion chromatograph at the University of Tasmania (Curran and Palmer, 2001). For this analysis, discrete samples were scraped from the chemistry sticks using a microtome blade in a laminar flow hood to provide subsamples at a resolution of approximately $5 \mathrm{~cm}$ along the length of each ice stick. During 2005, six parallel archived sticks of ice from this core were re-analyzed by ion chromatography. For this analysis, subsampling of the ice sticks was carried out using a melter system coupled to a fraction collector. A later study in 2007 re-analyzed a further four parallel ice sticks. These ice sticks were cut from the archived half of the core, and subsampled by replicating the microtome scraping method used in 2000 .

Comparison of the chemistry data between the repeat analyses in 2000, 2005 and 2007 (Fig. 1; Table 1) shows excellent reproducibility for conservative ions that do not diffuse through ice. For example, negligible mean losses of $1 \pm 5 \%$ and $2 \pm 4 \%$ are observed for the comparison of the chloride concentrations measured in 2000 with the later

Table 1. Summary of changes in MSA and chloride concentrations in ice-core samples archived using different storage methods. Error values give the $95 \%$ confidence range around a least-squares regression between early and later analyses of MSA and chloride

Core

Storage method

Length of storage

years
Change in MSA concentration Change in chloride concentration $\%$
$-1 \pm 5$

$-2 \pm 4$

$+5 \pm 2$

Half-core archive

Bottled samples

Bottled samples
$-39 \pm 3$

$+5 \pm 4$

$+9 \pm 3$ 


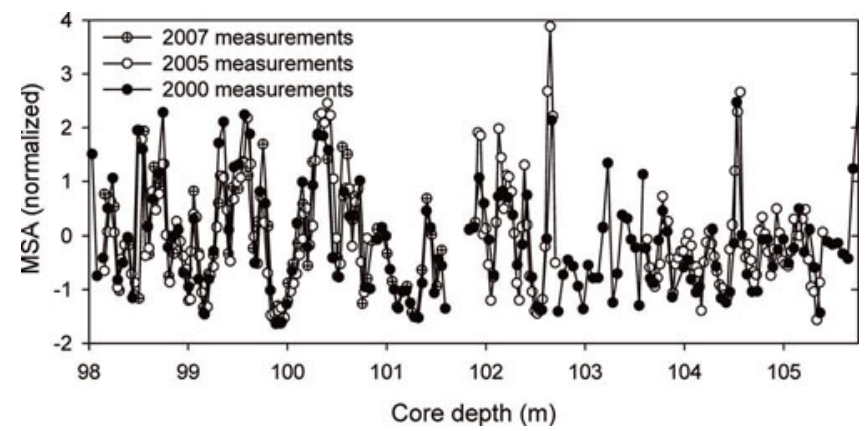

Fig. 2. Normalized MSA records from the DSS99 core show good reproducibility of the interannual MSA record, despite losses in the absolute concentration of MSA during frozen storage of ice sticks. The three datasets were normalized to a mean of 0 and a standard deviation of 1 over their common interval.

measurements made in 2005 and 2007, respectively (error values give the $95 \%$ confidence range around a leastsquares regression). In contrast, comparison of the 2000 and 2005 measurements of MSA indicates that on average $24 \pm 4 \%$ of the MSA had been lost from the chemistry sticks after 5 years of frozen storage. This finding is confirmed by the replicate measurements in 2007, where it was observed that the mean MSA loss after 7 years of storage had increased to $39 \pm 3 \%$.

This observed MSA loss from archived ice sticks is consistent with previous measurements of profiles of MSA loss from the margin of archived ice cores (Smith and others, 2004). This earlier study measured gradients of MSA loss in the outer $3 \mathrm{~cm}$ of core segments archived for 14.5 years. Using these profiles of MSA loss, a solid-ice diffusion coefficient for MSA of $2 \times 10^{-13} \mathrm{~m}^{2} \mathrm{~s}^{-1}$ at storage temperatures of -18 to $-20^{\circ} \mathrm{C}$ was calculated. Preliminary calculations suggest that the MSA losses we observe from frozen ice sticks after 5 and 7 years of storage are broadly consistent with the losses expected based on diffusion of MSA (personal communication from T. van Ommen, 2007). This suggests that with further testing using core sections with different geometries and storage histories it may be possible to use the diffusion coefficient of MSA to model the effect of MSA loss during storage.

Importantly, while there has been a significant amount of MSA loss from the archived ice sticks, the preservation of annual and interannual variability in the MSA record remains good. This agreement becomes clear when the MSA datasets from the 2000, 2005 and 2007 analyses are normalized (Fig. 2). Hence, while the absolute concentration of MSA is reduced over time, there is still potential to recover a useful environmental record of interannual MSA variability from ice that has been archived as cores or sticks. It is likely, however, that the quality and reliability of this signal will be reduced with progressively longer storage periods.

\section{BOTTLED SAMPLES: METHODS AND RESULTS}

The effect of bottled storage on MSA preservation was examined using ice samples from two cores collected by the British Antarctic Survey. One core was drilled on Dyer Plateau during the 1988/89 austral summer, and the other on Beethoven Peninsula in 1992/93 (Pasteur and Mulvaney, 2000). Both cores were transported frozen to the United Kingdom. The cores were subsampled at a monthly resolution using a bandsaw that had been cleaned with frozen ultra-pure water. These subsamples were melted into precleaned $100 \mathrm{~mL}$ polythene bottles and stored frozen at $-20^{\circ} \mathrm{C}$. The $100 \mathrm{~mL}$ bottles were essentially full for the Beethoven Peninsula samples but were only partially filled for the Dyer Plateau core.

The British Antarctic Survey first developed the capability for measuring MSA in the early 1990s. These analyses were
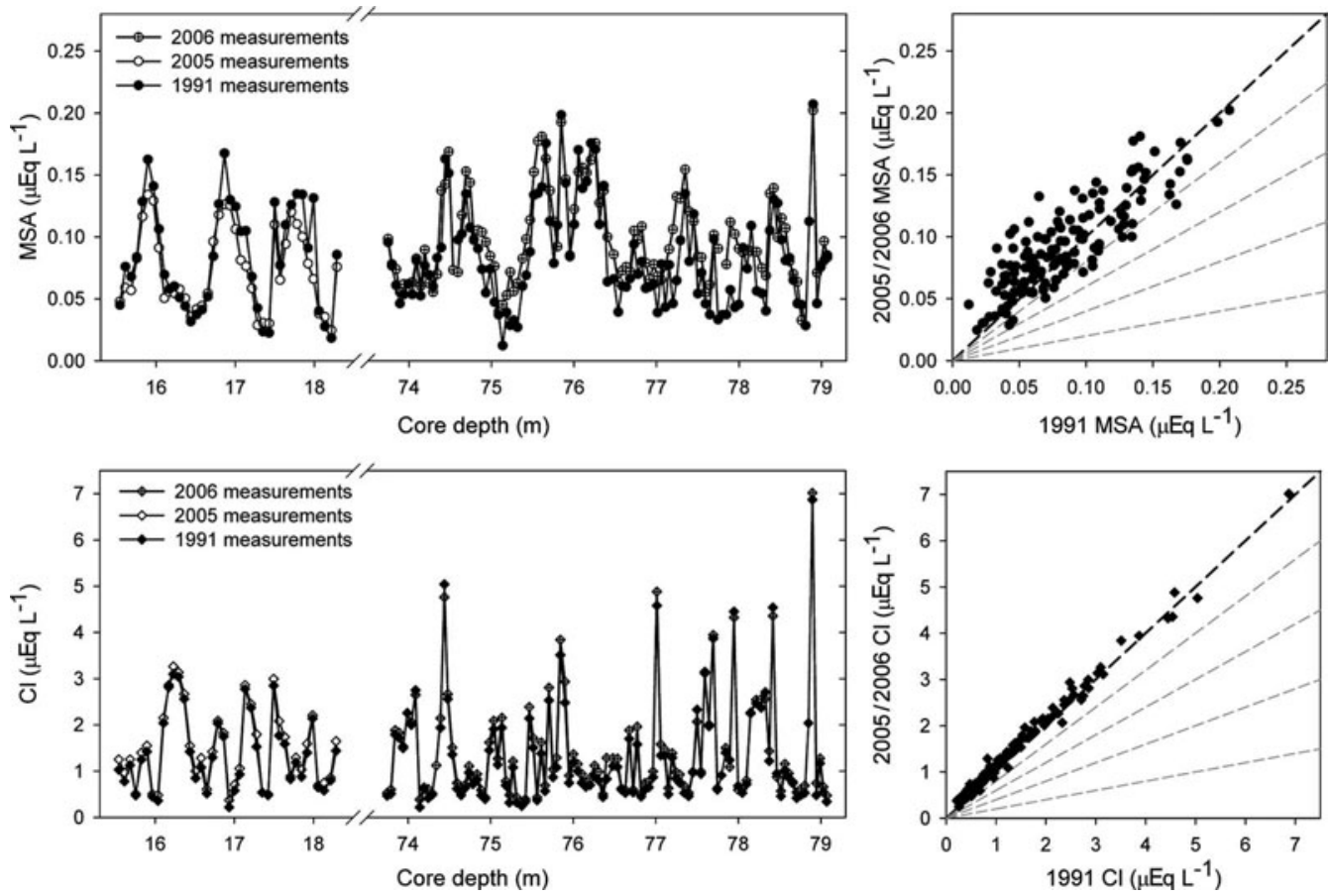

Fig. 3. Details as in Figure 1, but for chemical measurements of bottled ice samples from the Dyer Plateau core made during 1991, 2005 and 2006. The ice samples stored in bottles show no evidence for MSA loss during storage. 

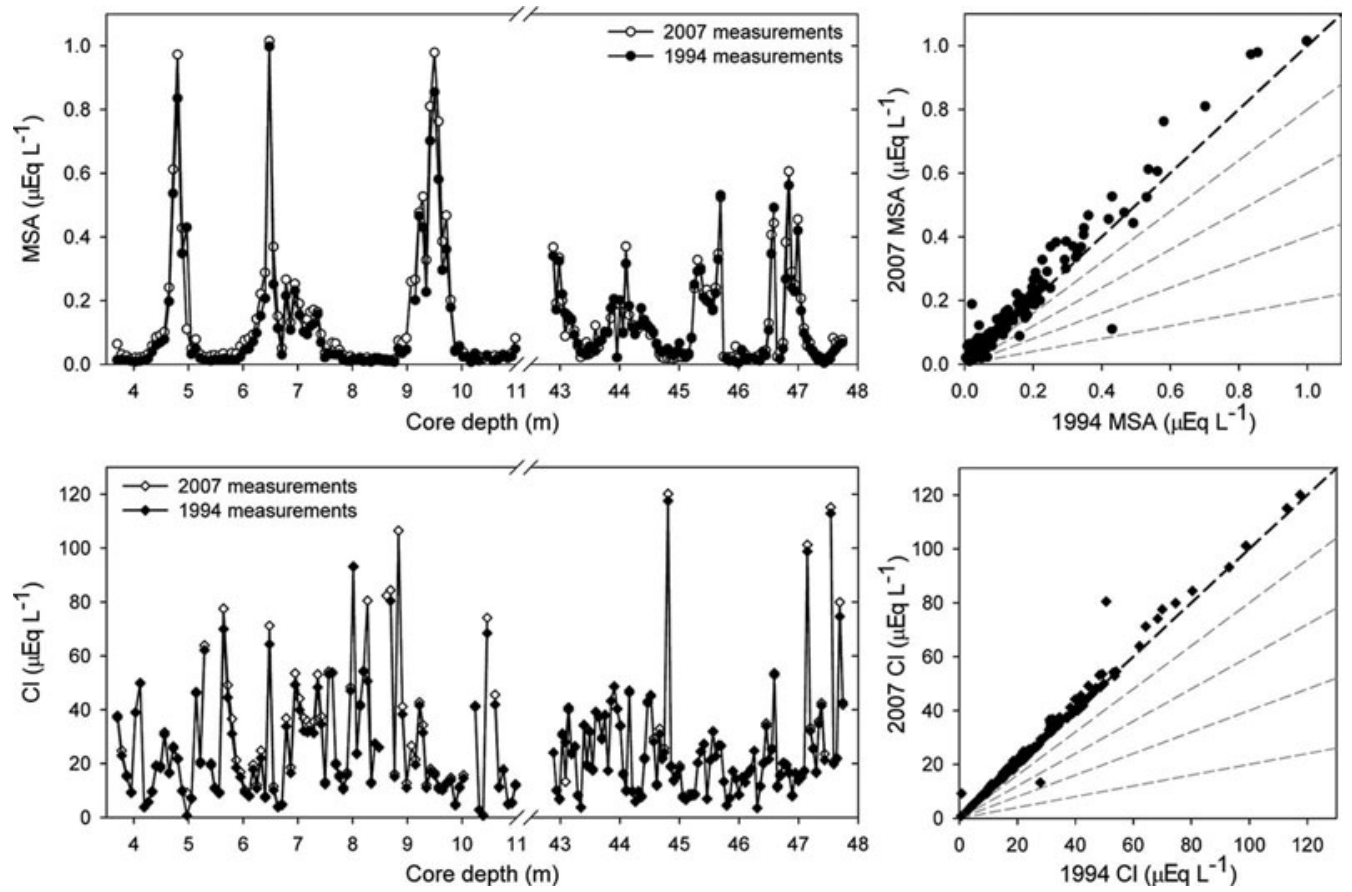

Fig. 4. Details as in Figure 1, but for chemical measurements of bottled ice samples from the Beethoven Peninsula core made during 1994 and 2007. The ice samples stored in bottles show no evidence for MSA loss during storage.

performed using Dionex ion chromatographs, and sample handling and analyses took place in a class 100 clean laboratory. In April 1991, two sections of the Dyer Plateau core were first analyzed for MSA (Mulvaney and others, 1992). Two sections of the Beethoven Peninsula core were first analyzed for MSA in mid-1994 (Pasteur and Mulvaney, 2000). Following a number of years in frozen storage, the bottled ice samples from these core sections were reanalyzed for MSA in July 2005 and November 2006 (Dyer Plateau core) and May 2007 (Beethoven Peninsula core) as part of a programme to increase the coverage of MSA records around Antarctica by analyzing archived ice cores. Typical analytical precision for the more recent MSA analyses is $\pm 5 \%$.

The re-analyzed bottled samples from the Dyer Plateau (Fig. 3) and Beethoven Peninsula (Fig. 4) cores show excellent agreement with the earlier MSA analyses performed on these cores (Table 1). For the Dyer Plateau core, the 143 duplicate samples show a slight overall enrichment in the more recent MSA analyses of $5 \pm 4 \%$. Duplicate measurements of chloride also show a mean $5 \pm 2 \%$ enrichment, suggesting that the slight difference between the early and recent MSA results is due to the analytical limits of the precision of the measurements and calibration. The comparison of early and recent MSA results for the Dyer Plateau samples does reveal a considerably larger scattering in the MSA results than is observed for chloride. Examination of the two MSA time series suggests that this scatter may be associated with increased noise in the early MSA analyses, where the annual cycle in MSA is less well defined. Thus it is possible that the scatter in the MSA comparison for this core may be due to a lower precision in the newly developed MSA measurements that were made in 1991. Despite this, the results clearly show that there has been no systematic loss of MSA due to storage of the ice samples.

The coastal ice-core site at Beethoven Peninsula experiences large seasonal cycles in ion chemistry and this provides a test for MSA reproducibility over a much greater range of concentrations than the Dyer Plateau core. The 192 duplicate analyses of bottled samples from the Beethoven Peninsula core again display excellent reproducibility of the absolute concentrations and seasonal variability of MSA. Overall a mean enrichment of $9 \pm 3 \%$ is observed in the recent MSA measurements, which may be due to minor calibration differences over the extreme range of MSA concentrations in this core. For comparison, the recent chloride measurements also show a slight enrichment of $4 \pm 1 \%$ when compared with the early chloride measurements from this core.

Overall, our results demonstrate that is it possible to prevent MSA loss through the archiving of ice-core chemistry samples in bottles. This appears to hold true even over long storage times, with the bottled samples analyzed here showing no evidence for MSA loss even after storage periods of 15 years. It is important to note that the repeat analyses performed here only measured the effect of bottled storage on MSA and chloride, and it is not clear how the quality of other chemical species may be influenced by bottled storage.

\section{IMPLICATIONS}

The findings of this study are consistent with earlier laboratory studies demonstrating that MSA is able to move in solid ice, resulting in a loss of MSA from archived ice cores. This means that ideally the MSA compositions of ice cores should be analyzed as soon after collection as possible. However, the excellent reproducibility of both the absolute values and seasonal structure of MSA in ice cores that have been refrozen into discrete bottled samples demonstrates that it is possible to archive ice cores in a way that preserves the original MSA composition. This preservation may depend upon limiting the surface area of the ice sample that interfaces with the atmosphere, or may instead 
be the result of chemical stabilization of MSA in ice samples that have been refrozen from liquid water. Understanding the mechanisms responsible for MSA preservation in bottled samples will have implications for establishing a bestpractice method for preserving samples for later MSA analysis, and this warrants further study in the future.

Importantly, this study has also shown that MSA loss during storage does not necessarily destroy the environmental information in ice cores that have been archived by the more conventional method of preserving sections of ice cut from the original core. MSA loss does not appear to alter the interannual signal in archived ice sticks, at least over storage times of a small number of years. It is critical to note, though, that the actual amount of MSA loss will vary with the geometry of the ice section and the amount of time that it has been stored. Because of this, the use of MSA records from archived ice sticks requires a consistent approach in order to prevent spurious results that could be caused by changes in the dimensions of archived ice sticks along a core, or differences in the length of time that sections of a single core have been stored prior to analysis.

The analysis of MSA in ice cores, including older archived cores, should make it possible to reliably increase the network of MSA records around Antarctica, provided that issues of MSA diffusion and loss during storage of the ice are considered. This requires that storage and analysis histories for ice-core MSA records are well documented. This will provide an improved understanding of the environmental processes that control MSA variability at different sites and allow for the development of regional reconstructions of Antarctica's sea-ice history.

\section{REFERENCES}

Abram, N.J., R. Mulvaney, E. Wolff and M. Mudelsee. 2008. Ice core records as sea ice proxies: an evaluation from the Weddell Sea region of Antarctica. J. Geophys. Res., 112(D15), D15101. (10.1029/2006)D008139.)

Curran, M.A.J. and G.B. Jones. 2000. Dimethyl sulfide in the Southern Ocean: seasonality and flux. J. Geophys. Res., 105(D16), 20,451-20,459.
Curran, M.A.J. and A.S. Palmer. 2001. Suppressed ion chromatography methods for the routine determination of ultra low level anions and cations in ice cores. J. Chromatogr., A., 919(1), 107-113.

Curran, M.A.J. and 6 others. 2002. Post-depositional movement of methanesulphonic acid at Law Dome, Antarctica, and the influence of accumulation rate. Ann. Glaciol., 35, 333-339.

Curran, M.A.J., T.D. van Ommen, V.I. Morgan, K.L. Phillips and A.S. Palmer. 2003. Ice core evidence for Antarctic sea ice decline since the 1950s. Science, 302(5648), 1203-1206.

Foster, A.F.M., M.A.J. Curran, B.T. Smith, T.D. van Ommen and V.I. Morgan. 2006. Covariation of sea ice and methanesulphonic acid in Wilhelm II Land, East Antarctica. Ann. Glaciol., 44, 429-432.

Fundel, F., H. Fischer, R. Weller, F. Traufetter, H. Oerter and H. Miller. 2006. Influence of large-scale teleconnection patterns on methane sulfonate ice core records in Dronning Maud Land. J. Geophys. Res., 111(D4), D04103. (10.1029/ 2005JD005872.)

Mulvaney, R., E.C. Pasteur, D.A. Peel, E.S. Saltzman and P.Y. Whung. 1992. The ratio of MSA to non-sea-salt sulphate in Antarctic Peninsula ice cores. Tellus, 44B(4), 295-303.

Pasteur, E.C. and R. Mulvaney. 1999. Laboratory study of the migration of methane sulphonate in firn. J. Glaciol., 45(150), 214-218.

Pasteur, E.C. and R. Mulvaney. 2000. Migration of methane sulphonate in Antarctic firn and ice. J. Geophys. Res., 105(D9), 11,525-11,534.

Pasteur, E.C., R. Mulvaney, D.A. Peel, E.S. Saltzman and P.Y. Whung. 1995. A 340 year record of biogenic sulphur from the Weddell Sea area, Antarctica. Ann. Glaciol., 21, 169-174.

Ravishankara, A.R., Y. Rudich, R. Talukdar and S.B. Barone. 1997. Oxidation of atmospheric reduced sulphur compounds: perspective from laboratory studies. Philos. Trans. R. Soc., Ser. B, 352(1350), 171-182.

Saigne, C. and M. Legrand. 1987. Measurements of methanesulphonic acid in Antarctic ice. Nature, 330(6145), 240-242.

Smith, B.T., T.D. van Ommen and M.A.J. Curran. 2004. Methanesulphonic acid movement in solid ice cores. Ann. Glaciol., 39, 540-544.

Welch, K., P.A. Mayewski and S.I. Whitlow. 1993. Methanesulfonic acid in coastal Antarctic snow related to sea-ice extent. Geophys. Res. Lett., 20(6), 443-446. 